\title{
Serving science through publishing
}

\author{
Guillem Aromí a, Patrick Gamez a,b, Leoní A. Barrios a, \\ Jordi Ribas ${ }^{c}$, Boris Le Guennic d
}

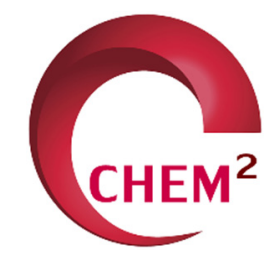

guillem.aromi@sci2.org, patrick.gamez@sci2.org, leoni.barrios@sci2.org, jordi.ribas@sci2.org, boris.leguennic@sci2.org iD

\author{
a Departament de Química Inorgánica i Orgànica, Universitat de Barcelona, Diagonal 645, 08028, \\ Barcelona-Spain \\ b Institució Catalana de Recerca i Estudis Avançats (ICREA) \\ c Departament de Ciència de Materials i Química Física and IQTCUB, Universitat de Barcelona, Diagonal \\ 645, 08028, Barcelona-Spain \\ d Institut des Sciences Chimiques de Rennes, UMR 6226 CNRS-Université de Rennes 1, 263 Avenue du \\ Genéral Leclerc, 35042 Rennes Cedex, France
}

We are delighted to welcome you to Chemistry Squared $\left(\right.$ Chem $\left.^{2}\right)$, the first specialized scientific journal of the academic non-profit association Science Squared $\left(S_{\text {cience }}{ }^{2}\right.$ ). This association has been created recently by a group of university scholars with the aim of promoting a new paradigm in scientific publishing. The virtues of the proposed scheme are, i) high scientific and technical standards, ii) open and universal access to scientific knowledge, iii) diminished costs for publishing, and iv) return to the scientific community of any benefits derived from the process of dissemination of Science, in a fair and transparent manner. We believe that this system represents a more beneficial one than most of the current schemes because it ensures the reputation of high quality and rigorous Science while guaranteeing the free and easy access to it at low cost. Therefore, it also helps to reduce the financial burden of scientific publishing, which is mostly endured by public agencies. The proposition of Science 2 intends to stimulate this avenue among scientists by entertaining a sustained and transparent funding program for research training with all the benefits derived from its activities. The key for the success of this publishing method is the active and rigorous engagement of the scientific community. Scholars who decide to contribute in any way to the academic endeavours of science $^{2}$ must know that in this manner, they are in fact helping the scientific community and benefiting global society. We want to thank all these scientists around the world that have already offered their support and engagement with Science ${ }^{2}$ by becoming a part of the Editorial or Advisory Boards of Chem².

Chem ${ }^{2}$ is a multidisciplinary journal that publishes high-level original research on any field of Chemistry. It is the first of what should be a long list of journals in different scientific areas issued and entertained by Science $^{2}$. We are confident in rapidly enlarging the community of scientists and scholars engaged in a scheme for the dissemination of new knowledge that puts the researcher at the centre of the process, makes Science universal and alleviates society from the costs of publishing while helping to foster the career of young scientists. It is only on your hands.

Published online: 01 December 2017

ORCID ID for authors

Guillem Aromí: 0000-0002-0997-9484

Patrick Gamez: 0000-0003-2602-9525

Leoní A. Barrios: 0000-0001-7075-9950

Jordi Ribas: 0000-0003-4088-6187

Boris Le Guennic: 0000-0003-3013-0546 